\title{
LAND USE AND LAND COVER CHANGES AND URBAN SPRAWL IN RIYADH, SAUDI ARABIA: AN ANALYSIS USING MULTI-TEMPORAL LANDSAT DATA AND SHANNON'S ENTROPY INDEX
}

\author{
M. T. Rahman ${ }^{\mathrm{a}}$ \\ ${ }^{a}$ King Fahd University of Petroleum and Minerals, Department of City and Regional Planning, KFUPM Box 5053 \\ Dhahran, Saudi Arabia- mtr@kfupm.edu.sa
}

Commission WG VIII/8

KEY WORDS: Land Use, Land Cover Change, Shannon's Entropy, Riyadh

\begin{abstract}
:
The city of Riyadh, Saudi Arabia has experienced rapid population growth and urban expansion over the past several decades. Due to such growth, the capital city faces many short and long-term social and environmental consequences. In order to monitor and mitigate some of these consequences, it is essential to examine the past changes and historical growth of the city. It is also essential to measure its urban sprawl over the past few decades. The objective of this study is to fulfil these goals. It does so by first examining the historical growth of the city of Riyadh. To do so, Landsat data over the past two and half decades are classified using a combination of supervised and unsupervised classification techniques. Based on the classification results, the study then uses Shannon's Entropy to measure the urban sprawl in the city. The results show that from 1990-2009, the urban built-up area of the city has increased by $90 \%$ in the western, south-eastern, and northern parts. The Shannon's entropy values show that the city is dispersing towards the outskirts of the city. The results from this study will assist city planners and government officials to plan, reduce, and perhaps mitigate some of the social and environmental consequences and enable the growth of the city in a sustainable manner in the near future.
\end{abstract}

\section{INTRODUCTION}

The capital of Saudi Arabia, Riyadh, has experienced rapid expansion and population growth over the past several decades (Aina, Merwe, \& Alshuwaikhat, 2008). Such expansion and increasing population in the cities will have several environmental and social consequences (Ahmed, Kamruzzaman, Zhu, Rahman, \& Choi, 2013; Dewan, Kabir, Nahar, \& Rahman, 2012; Dewan \& Yamaguchi, 2009). In order to assess and reduce these consequences, it is essential that the changes in the city's land use and land cover is examined and the presence of urban sprawl is measured. Modern advancement of GIS and Remote Sensing technologies have made them an essential tool for examining land use and land cover changes (Hassan, Mahmud-Ul-Islam, \& Rahman, 2015; Rahman \& Rashed, 2015; Yuan, Sawaya, Loeffelholz, \& Bauer, 2005). They have also been useful for measuring urban sprawl of various cities in the world (Bhatta, Saraswati, \& Bandyopadhyay, 2010). With the use of historical remote sensing data, this study examined the land use and land cover changes in the city of Riyadh, the capital of the Kingdom of Saudi Arabia. To do so, this study proposes a combination of supervised and unsupervised classification methods. Using the classification results, the study also measured the decadal urban sprawl of the city using the Shannon's Entropy Index in a GIS platform.

\section{STUDY AREA}

Riyadh is located in the central part of the Arabian Peninsula. The city currently has a population of 5.25 million (CDSI, 2010). Most of the residents live in the eastern parts where the city is fairly flat. The western parts are hilly with the Wadhi Hanifa flowing from the northwest to the south-eastern parts of the city. Being situated in Western Asia, the city has subtropical desert dry climate. Since most of the changes in the landscape occurred in the eastern parts of the city, it was chosen as the area of interest for this study. The study area contains 16 municipalities with 159 neighbourhoods and has an area of approximately 2824 sq. km. (Figure 1).

\section{METHODOLOGY}

\subsection{Data Collection and Pre-Processing}

Due to their affordability, moderate resolution, and historical archival availability, three Landsat imageries from the United States Geological Survey (in "Level 1T" format) were acquired for this study. The Level $1 \mathrm{~T}$ data were already provided by USGS with geometric and systematic radiometric corrections processed through ground control points (USGS, 2015). Table 1 highlights the details about the data.

\begin{tabular}{|l|c|c|c|}
\hline \multicolumn{1}{|c|}{ Date } & Sensor & Path/Row & Format \\
\hline August $31^{\text {st }}, 1990$ & Landsat-5 & $165 / 43$ & GeoTIFF \\
July $28^{\text {th }}, 1998$ & Landsat-7 & $165 / 43$ & GeoTIFF \\
August $19^{\text {th }}, 2009$ & Landsat-7 & $165 / 43$ & GeoTIFF \\
\hline
\end{tabular}

Table 1. Characteristics of the data used in study

\subsection{Image Classification}

A combination of unsupervised classification method was used to classify the landscape of the city into three major classes using the Anderson Level 1 classification scheme. The details of the land-cover classes are given in Table 2. The images were first classified using the ISODATA unsupervised classified method. The Iterative Self-Organizing Data Analysis Technique Algorithm, commonly known as ISODATA classification method is an unsupervised classification technique that is a 


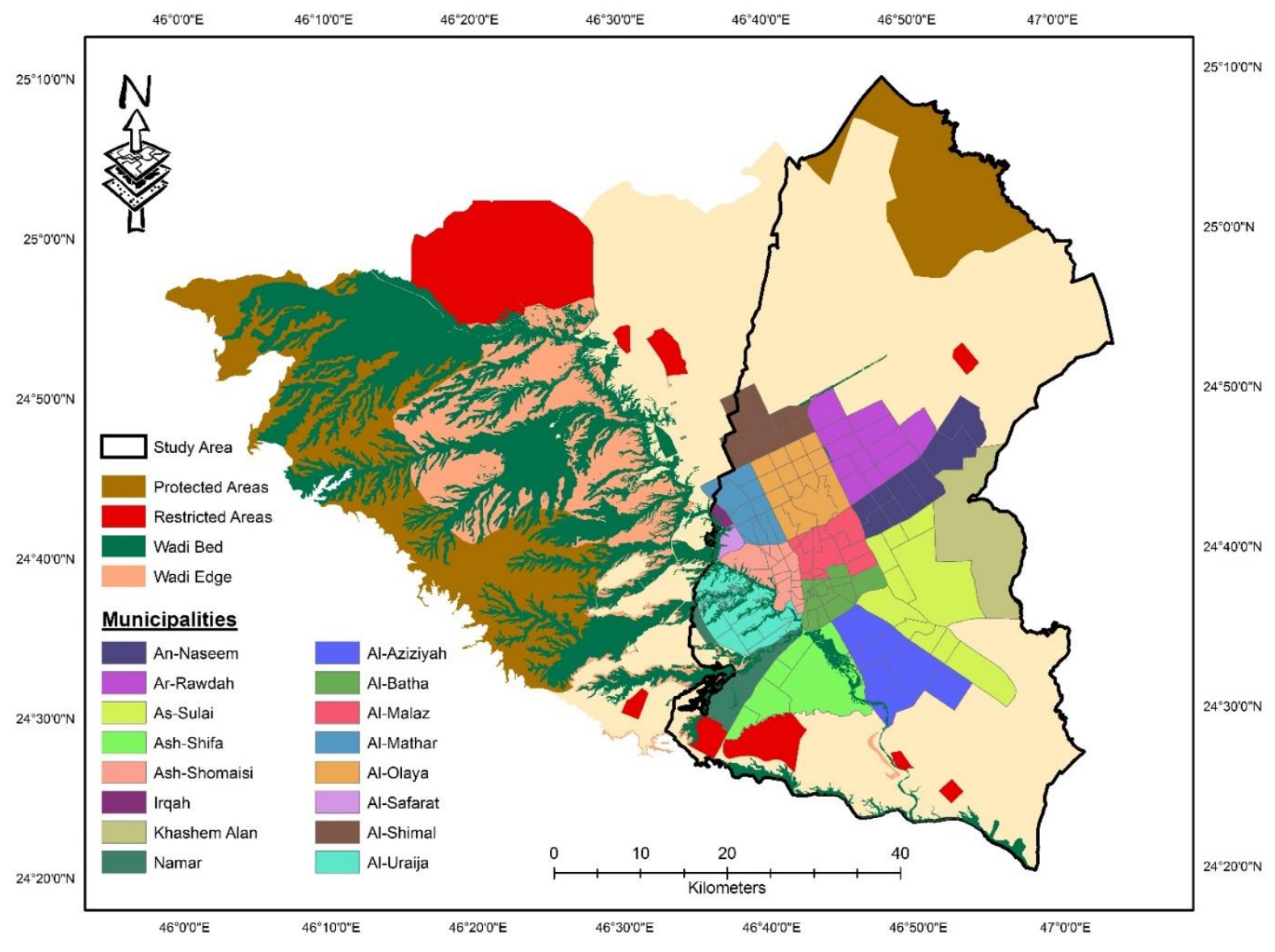

Figure 1. Study area boundary in the City of Riyadh

variant of the K-means clustering algorithm (Campbell \& Wynne, 2011). The algorithm works by first randomly placing cluster canters in the dataset and then assigning pixels to each centre based on the minimum distance between the pixels and the centres. It then calculates the standard deviation within each cluster and the distance between the cluster centres. A second iteration of the process is performed with new cluster centres. The process is repeated and in each iteration, two clusters are merged if the distance between them is less than some predefined minimum distance. The iteration stops when there are no significant changes in the cluster statistics or the maximum number of user-defined iterations are reached. In this study, the ISODATA clustering algorithm was applied on the datasets from the three years in ENVI v. 5.0 using the following input parameters: number of classes (minimum of 5, maximum of 15), maximum iterations (15), change threshold (5\%), minimum number of pixel in class (5), maximum class standard deviation (1), minimum class distance (5), and maximum number merge pairs (2).

Once the data were classified using ISODATA classification method, it was processed further using a maximum likelihood supervised classification (MLC) technique (Campbell \& Wynne, 2011; Jensen, 2004). The MLC method was conducted using signatures from a total of 174 training sites chosen from the three LULC classes (vegetation, bare soil/sand, and urban built up area). The training sites were chosen using stratified random sampling method. Once the final classification was complete, misclassified pixels were manually corrected and a 3 by 3 grid cell low-pass filtering was used to reduce the "salt-and-pepper" effect in the classified results. Finally, a post-classification change detection method was used to compare the changes.

\begin{tabular}{|c|c|}
\hline $\begin{array}{c}\text { Land Cover } \\
\text { Type }\end{array}$ & Description \\
\hline $\begin{array}{c}\text { Urban/Built- } \\
\text { up Areas }\end{array}$ & $\begin{array}{l}\text { All infrastructure including residential, } \\
\text { mixed use, commercial, industrial areas, } \\
\text { villages, road network. }\end{array}$ \\
\hline Vegetation & $\begin{array}{l}\text { Agricultural lands, grassland, natural } \\
\text { vegetation, trees, gardens, parks, and play } \\
\text { grounds. }\end{array}$ \\
\hline Soil \& Sand & $\begin{array}{c}\text { Bare soils, open spaces, excavation sites, } \\
\text { developed land, sand, and all land cover } \\
\text { types. }\end{array}$ \\
\hline
\end{tabular}

Table 2. Description of land cover types used in the study

To examine the accuracy of the classification results, reference points selected through stratified random sampling method from 168 locations distributed across the study area were chosen. Historical LULC maps (in ArcGIS shapefile format) along with recent high resolution GeoEye image were then collected and geometrically corrected with the Landsat imageries and the ground truth data. The classified results were then compared with the LULC maps, GeoEye 


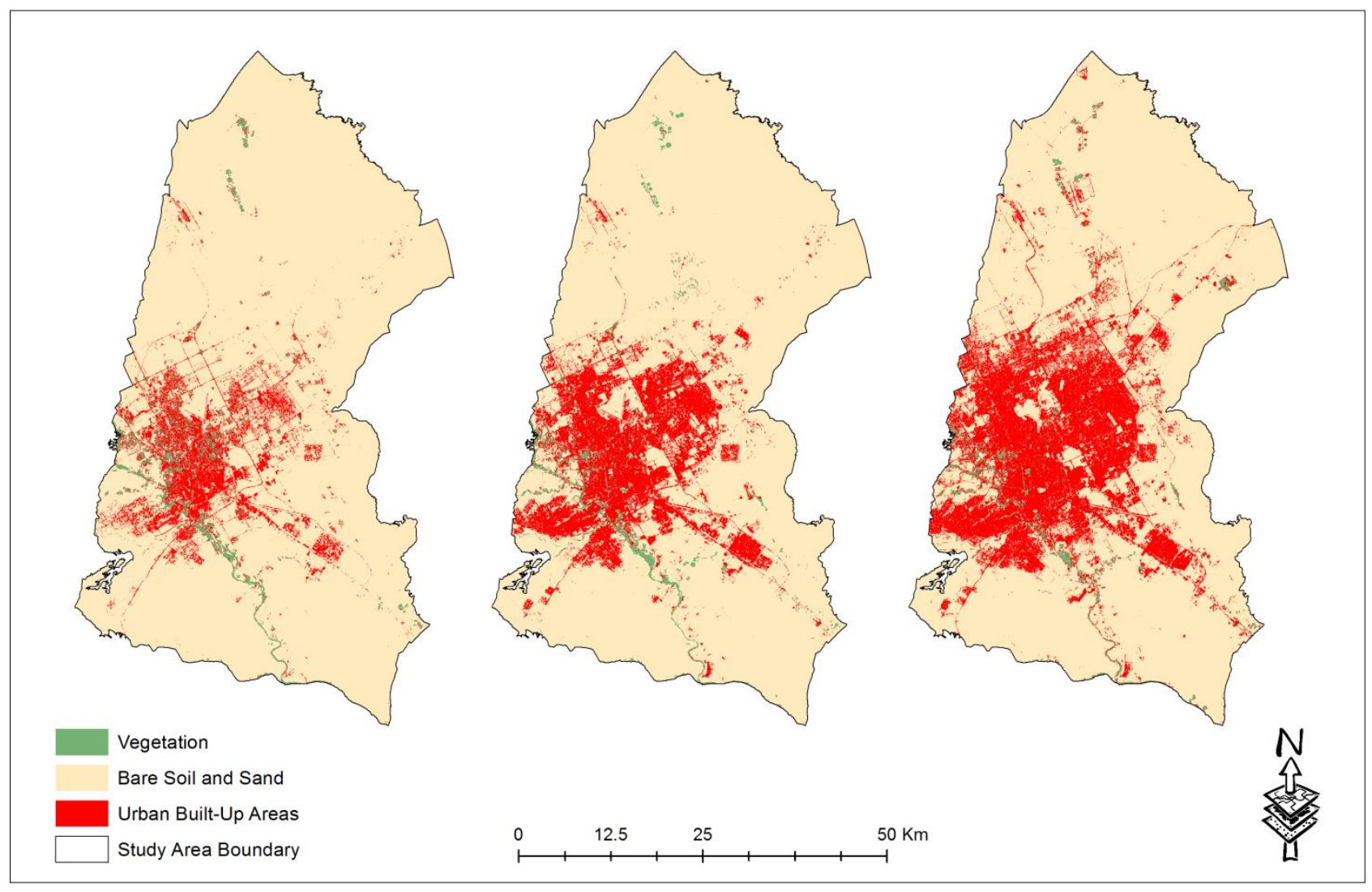

Figure 2. LULC in the study area in 1990 (left), 1998 (center), and 2009 (right)

image, and the reference points. Contingency tables were then created and the producer's accuracy (PA), user's accuracy (UA), overall accuracy (OA), and the kappa coefficient were calculated to assess the accuracy of the classified results.

\subsection{Urban Sprawl Measurement}

Numerous challenging methods have been used to define, measure, and quantify urban sprawl. However, the integration of Shannon's Entropy and GIS tools is one of the simplest and efficient methods to measure urban sprawl (Cabral, Augusto, Tewolde, \& Araya, 2013). Shannon's entropy $\left(E_{n}\right)$ measures the degree of concentration and dispersion of a geographic variable among $n$ zones. It has been used to examine whether land development is dispersed or compact in several cities of the world (Araya \& Cabral, 2010; Rahman, 2016; Sun, Forsythe, \& Waters, 2007) To perform the analysis, the three classified maps were first reclassified into two categories: built-up and non-built up areas. Then ith numbers of concentric circles or buffers are drawn from the center of the city. As in other Islamic cities, the grand mosque is considered to be center and the oldest part of the city. Therefore, the buffers were drawn surrounding the mosque. The zonal statistics function of ArcGIS v. 9.3 was then used to calculate the amount of built up area within each circle and relative entropy values were calculated for each year. Relative Shannon's entropy scales the standard entropy values from 0 to 1 and is beneficial for comparing entropy values from multiple years. The relative entropy for the three years was calculated by,

$$
E_{n}=\sum_{i}^{n} p_{i} \log \left(1 / p_{i}\right) / \log (n)
$$

Where $p_{i}=\frac{x_{i}}{\sum_{i}^{n} x_{i}}$ and $x_{i}$ is the density of land development, which equals the amount of built-up land divided by the total amount of land in the $i$ th zone in $n$ total zones (Sun et al., 2007). Entropy values closer to 0 indicates the distribution is very compact and values closer to 1 would suggest an evenly dispersed distribution across space.

\section{RESULTS \& DISCUSSIONS}

The spatial distributions of the land use and land cover and their areal statistics for the three years are given in Figure 2 and Table 3. The overall accuracies of the classified results were 83\% (1990), 85\% (1998), and 89\% (2009). The classified results show that the city is expanding in the western, south-eastern, and northern parts of the city. Between 1990 and 2009, the urban built up area in the city almost doubled (90\%). The increase is due to population increase due to migration of the local villagers and expatriates migrating into the city for the better employment, education, and health facilities. The expansion is also due to the economic prosperity of the Kingdom (Aina et al., 2008). The vegetation has also increased during this last two decades. This increase in the vegetation is due to the various initiatives to make the city green so that it is at par with other global cities (Garba, 2004). Finally, the increase in vegetation and the urban built up area is causing the bare soil to decrease. Such modification of the landscape will have several consequences including rise in urban land surface 


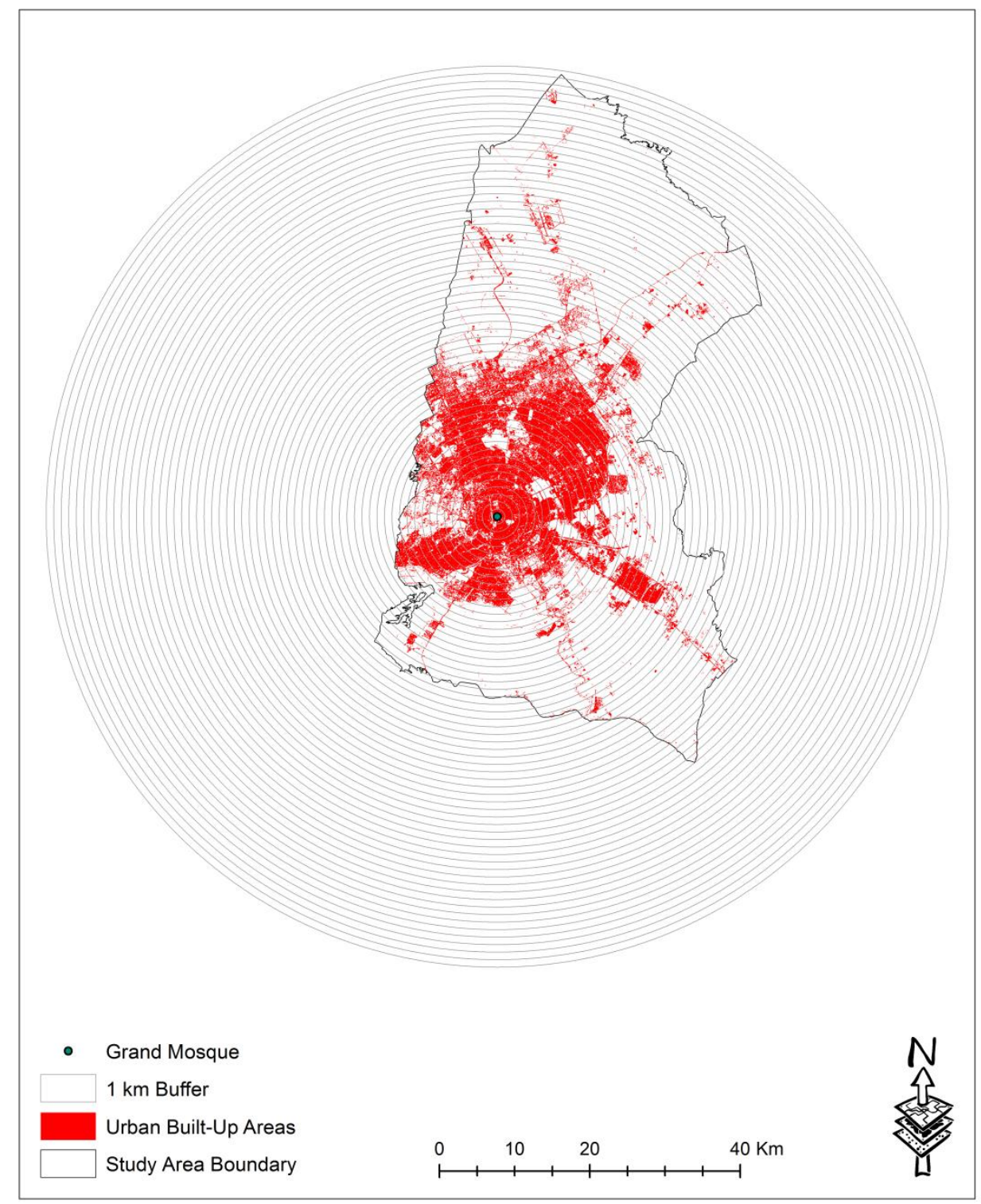

Figure 3. Buffers drawn to calculate Shannon's Entropy using 2009 LULC classified data.

temperature and formation of urban heat islands, rise in energy consumption, air pollution, and increasing costs in living expenses To measure the urban sprawl, Shannon's entropy was used as an index in this study. A total of 60 buffers were drawn to cover the entire study area (Figure 3). The relative Shannon's entropy for the three years are as follows: 0.65 (1990), 0.68 (1998), and 0.71 (2009). The changes in the Shannon's entropy suggest the city is getting dispersed towards the outskirts of the city in the northern, southern, and south-eastern parts of the city. The Shannon's entropy results are lower than other cities in kingdom (Rahman, 2016) and in the world including China and Canada (Li \& Yeh, 2004; Sun et al., 2007).

\begin{tabular}{|c|c|c|c|}
\hline Land Cover Type & 1990 & 1998 & 2009 \\
\hline Urban/Built-up & 330 & 477 & 626 \\
Areas & 38 & 77 & 119 \\
Vegetation & 2456 & 2269 & 2079 \\
Soil \& Sand & \\
\hline
\end{tabular}

Table 3. Area in Sq. Km of the land covers from 1990-2009

\section{CONCLUSIONS}

This study has used historical land use and land cover data to examine the land use and land cover changes in the capital city of Saudi Arabia from 1990-2009. It has also measured the urban sprawl in the city. The results show that the city is expanding towards the southern, south-eastern, and northern parts. In addition to increasing built-up area, the city is also increasing the amount of vegetation. However, such growth is causing the bare soil to decrease. The growth is causing the dispersion of the city in the outskirts of the city, as evidenced by the Shannon's entropy values. The results from this study will be beneficial to the planners and government officials of the City. It will allow them to examine the growth of the city and compare it to the previous masterplan of the city. It will also allow them to examine the vacant lands of the city and examine how it can be developed in the future in a sustainable manner. 


\section{ACKNOWLEDGEMENTS}

I am very grateful to the Deanship of Scientific Research at King Fahd University of Petroleum and Minerals for providing their generous financial support to attend the conference and present this paper.

\section{REFERENCES}

Ahmed, B., Kamruzzaman, M., Zhu, X., Rahman, M. S., \& Choi, K., 2013. Simulating Land Cover Changes and Their Impacts on Land Surface Temperature in Dhaka, Bangladesh. Remote Sensing, 5(11), pp. 5969-5998.

Aina, Y. A., Merwe, J. H. V., \& Alshuwaikhat, H. M., 2008. Urban Spatial Growth and Land Use Change in Riyadh: Comparing Spectral Angle Mapping and Band Ratioing Techniques. In: Proceedings of the academic track of the 2008 Free and Open Source Software for Geospatial (FOSS4G) Conference, incorporating the GISSA 2008 Conference, pp. 51-57.

Al-sharif, A. A. A., Pradhan, B., Shafri, H. Z. M., \& Mansor, S., 2013. Spatio-temporal analysis of urban and population growths in tripoli using remotely sensed data and GIS. Indian Journal of Science and Technology, 6(8), 5134-5142.

Araya, Y. H., \& Cabral, P., 2010. Analysis and Modeling of Urban Land Cover Change in Setúbal and Sesimbra, Portugal. Remote Sensing, 2(6), pp. 1549-1563.

Bhatta, B., Saraswati, S., \& Bandyopadhyay, D., 2010. Urban sprawl measurement from remote sensing data. Applied Geography, 30(4), pp. 731-740.

Cabral, P., Augusto, G., Tewolde, M., \& Araya, Y., 2013. Entropy in Urban Systems. Entropy, 15(12), 52235236. http://doi.org/10.3390/e15125223

Campbell, J. B., \& Wynne, R. H., 2011. Introduction to Remote Sensing (5th ed.). Guilford Press. Retrieved from

http://books.google.com.sa/books?id=zgQDZEya6foC

CDSI., 2010. Statistical Yearbook. Retrieved October 15, 2014, from http://www.cdsi.gov.sa/yb46/Pages/MixFPage.htm

Dewan, A. M., Kabir, M. H., Nahar, K., \& Rahman, M. Z., 2012. Urbanisation and environmental degradation in Dhaka Metropolitan Area of Bangladesh. International Journal of Environment and Sustainable Development, 11(2), pp. 118-147.

Dewan, A. M., \& Yamaguchi, Y., 2009. Land use and land cover change in Greater Dhaka, Bangladesh: Using remote sensing to promote sustainable urbanization. Applied Geography, 29(3), pp. 390-401.

Garba, S. B., 2004. Managing urban growth and development in the Riyadh metropolitan area, Saudi Arabia. Habitat International, 28(4), pp. 593-608.

Hassan, S., Mahmud-Ul-Islam, S., \& Rahman, M. T., 2015. Integration of Remote Sensing and GIS to Assess Vulnerability of Environmental Degradation in NorthWestern Bangladesh. Journal of Geographic
Information System, 7, pp. 494-505.

Igbokwe, J. I., 2013. Identification of Urban Sprawl Using Remote Sensing and GIS Technique: A Case Study of Onitsha and its Environs in Southeast, Nigeria. International Journal of Remote Sensing and Geoscience, 2(6), pp. 41-49.

Jensen, J. R., 2004. Digital change detection. In Introductory digital image processing: A remote sensing perspective (pp. 467-494). New Jersey: Prentice-Hall.

Li, X., \& Yeh, A. G.-O., 2004. Analyzing spatial restructuring of land use patterns in a fast growing region using remote sensing and GIS. Landscape and Urban Planning, 69(4), pp. 335-354.

Mallupattu, P., \& Reddy, J. S., 2013. Analysis of land use/land cover changes using remote sensing data and GIS at an Urban Area, Tirupati, India. The Scientific World Journal, 2013(Figure 1), 1-6. Retrieved from http://www.hindawi.com/journals/tswj/2013/268623/a bs/

Rahman, M. T., 2016. Detection of Land Use/Land Cover Changes and Urban Sprawl in Al-Khobar, Saudi Arabia: An Analysis of Multi-Temporal Remote Sensing Data. ISPRS International Journal of GeoInformation, 5(2), pp. 15.

Rahman, M. T., \& Rashed, T., 2015. Urban tree damage estimation using airborne laser scanner data and geographic information systems: An example from 2007 Oklahoma ice storm. Urban Forestry \& Urban Greening, 14(3), pp. 562-572.

Sun, H., Forsythe, W., \& Waters, N., 2007. Modeling Urban Land Use Change and Urban Sprawl: Calgary, Alberta, Canada. Networks and Spatial Economics, 7(4), pp. 353-376.

USGS., 2015. LANDSAT 8 (L8) DATA USERS HANDBOOK Version 1.0 June 2015 (Vol. 8).

Yuan, F., Sawaya, K. E., Loeffelholz, B. C., \& Bauer, M. E., 2005. Land cover classification and change analysis of the Twin Cities (Minnesota) Metropolitan Area by multitemporal Landsat remote sensing. Remote Sensing of Environment, 98(2-3), pp. 317-328. 